\title{
ON OUTSOURCED ABATEMENT SERVICES: MARKET POWER AND EFFICIENT ENVIORENMENTAL REGULATION
}

\author{
DAMIEN SANS ${ }^{\mathrm{a}}$, SONIA SCHWARTZ ${ }^{\mathrm{b}}$ AND HUbERT STAHN ${ }^{\mathrm{c}}$
}

\begin{abstract}
In this paper, we consider competitive polluting firms that outsource their abatement activity to an upstream imperfect competitive eco-industry to comply with environmental regulation. In this case, we show that an usual environmental policy based on a Pigouvian tax or a pollution permit market reaches the first-best outcome. The main intuition is based on the idea that purchasing pollution reduction services instead of pollution abatement inputs modifies for each potential tax rate (or out of the equilibrium permit price) the nature of the arbitrage between pollution and abatement. This induces a demand for abatement services which is, at least partially, strongly elastic and therefore strongly reduces upstream market power. This argument is first illustrated with an upstream monopoly selling eco-services to a representative polluting firm under a usual Pigouvian tax. We then progressively extend the result to permit markets, heterogeneous downstream polluters and heterogeneous upstream Cournot competitors.
\end{abstract}

JEL Codes: Q58, D43.

Keywords: Environmental regulation, Eco-industry, Imperfect Competition, Abatement Outsourcing.

\section{INTRODUCTION}

The Environmental Goods and Services Sector (EGSS hereafter), in the Eurostat definition, comprises all entities in their capacity as 'environmental producers', i.e., undertaking the economic activities that result in products for environmental protection and resource management. ${ }^{1}$ This sector is currently of major interest to policy makers and is given wide coverage by most statistical institutes. ${ }^{2}$ While acknowledging that the EGSS remains moderate in size, these institutes stress the sector's exceptional growth rate, its capacity to generate new job opportunities and its export performance. For instance, in the

The authors wish to thank three anonymous referees for their helpful comments on the early version of this paper. The usual disclaim applies concerning the remaining errors. This work was supported by the Agence Nationale de la Recherche of the French government through the program "Investissements d'avenir" : the Labex AMSE (ANR-11-IDEX-0001-02) and the Labex IDGM+ (ANR-10-LABX-14-01). Financial support of the ANR GREEN-Econ (ANR-16-CE03-0005) is also gratefully acknowledged.

${ }^{a}$ Aix-Marseille University (Aix-Marseille School of Economics), CNRS, \& EHESS. damien. sansegmail. com

${ }^{\mathrm{b}}$ Corresponding author. CERDI, Université Clermont-Auvergne. sonia.schwartz@uca.fr

${ }^{\mathrm{c}}$ Aix-Marseille University (Aix-Marseille School of Economics), CNRS, \& EHESS. hubert. stahn@univ-amu. fr

${ }^{1}$ For a precise definition of the activities included in this sector, the reader is referred to the Eurostat (2016a) "HANDBOOK ON EGSS" and to Eurostat (2016b) "THE PRACTICAL GUIDE OF EGSS ACCOUNTS". For a description of the EGSS the reader is also referred to Sinclair-Desgagné (2008).

${ }^{2}$ Even though some methodological problems remain (see the UNEP (2014)report of UNEP (2014)), several empirical studies have recently sought to quantify the EGSS. For instance, the Canadian statistical institute conducts a biennial survey of the EGSS (http: //www.statcan.gc.ca /eng /survey /business /1209). In Europe, Eurostats has initiated a study over 28 member states (see http: //ec.europa.eu /eurostat /statisticsexplained /index.php /Environmental_goods_and_services_sector) based on a methodology described in Eutostats [2016]. 
European Union, output of EGSS in 2014 was estimated for EU-28 at EUR 710 billion (5.1\% of EU-28 GDP) and the employment for its production amounted to 4.2 million full-time equivalents (FTEs). The EGSS output-to-GDP ratio grew by nearly 2 percentage points between 2000 and 2011 and remained at the level of 5.1\%-5.2\% over the period $2012-2014$.

The strong development of the EGSS over the past two decades is basically due to the implementation, at least in developed countries, of more stringent environmental policies. On these new markets, traditional polluting industries purchase technologies, goods or services which reduce their emissions while simultaneously avoiding, at least partially, the additional costs these environmental policies entail. This outsourcing of, say, pollution abatement typically has no additional consequences on the implementation of these policies, insofar as the EGSS markets remain competitive. ${ }^{3}$ However, it is widely acknowledged that EGSS is controlled by global firms like $\mathrm{CH} 2 \mathrm{M}$ Hill, Veolia Environmental Services, Vivendi Environment or Suez Environnement operating worldwide. The Ecorys (2009) report on the European EGSS even states that $10 \%$ of the companies account for almost $80 \%$ of the operating revenue. This clearly suggests that there is market power in the EGSS sector.

To understand the implication of this fact, let us consider a situation with perfect competition in the downstream polluting industry and market power in the upstream ecoindustry. In this case, fewer abatement solutions are traded at a higher price than if there was perfect competition in the eco-industry. This means that the "private" marginal cost of pollution abatement is larger than the marginal production cost of an abatement good. Thus the regulator has an incentive to set the pollution price (i.e. the emission tax) above the marginal social cost of pollution, i.e. above the marginal damage, in order to provide the right incentives. Moreover, the strength of this distortion is closely related to the degree of market power of the eco-industry, and hence as is usual in industrial organization, to the elasticity of demand. But, this demand is endogenous: it is deduced from the cost minimization strategy of each polluting firm facing the environmental regulation. This means that the demand for abatement goods is mainly explained by the performance of the polluting firm with respect to this specific input, i.e. its marginal productivity to abate pollution. The elasticity of this demand is thus related to the change in this marginal productivity.

This is especially true of end-of-pipe remediation activities. In this case, abatement does not modify the production process and therefore does not affect the marginal contribution to pollution of each final product. This remediation simply reduces emissions and therefore the costs entailed by a Pigouvian tax (or the purchase of tradeable pollution permits). As a result, the literature claims that each polluting firm purchases abatement goods until the tax avoidance of the last unit of abatement good is equal to its price. Since the tax rate is constant, this suggests that each dirty firm perfectly knows (or even controls) the pollution abatement technology and incorporates this knowledge into his tax avoidance strategy. This is typically the case for a large number of goods such as filters, scrubbers or incinerators that help to abate pollution.

\footnotetext{
${ }^{3}$ If the abatement goods are delivered at their marginal cost to the other producers, the production of the final good remains cost efficient. In other words, there are no additional distortions in the optimal choice of the policy rule. This however does not exclude distortions induced by imperfect competition on the final market.
} 
However, the polluting by-products of the economic activity may simply be delivered to another firm, which operates the decontamination. This is clearly the case for solid as well as hazardous waste. Transportation, treatment and disposal rely, since a couple of years, on private service providers. The same holds, of course, for wastewater sewerage and treatment. Both activities counted, in 2014, for $41 \%$ of the total activity of the EGSS in Europe (EU-28). Site remediation, after the 2004 European directive on prevention and remediation of environmental damage (2004/35/CE), is another service that becomes widely outsourced to external suppliers (for other illustrations of the emergence of these specialized firms, see Durand and Sinclair-Desgagné (2012)). We call this "marketable environmental services". This term should however not be misinterpreted. Our definition only covers clean-up activities which are outsourced. If the object of the transaction forms part of the production process of the dirty firm, it is not, in our terminology, considered as a service. Moreover, we say that these marketable services are delivered at a given market price even if this one is dictated by market power. In other words, we exclude from the scope of this analysis any vertical bargaining between abaters and polluters which induces, for instance, a non-linear pricing rule. Moreover, with "marketable services", the dirty firm is not really concerned by how it is performed, simply because this firm does perhaps not have the required knowledge to perform this activity. The firm simply transfers its burden to an other specialized firm at a given price. This however modifies its purchasing behavior. By buying abatement services, this firm only makes a trade-off between the price of this service and the cost of compliance with an environmental regulation, i.e., without regard for the efficiency of the decontamination equipment. This means that the elasticity of the demand becomes infinite, at least over a given range of this function. This at least partially offsets upstream market power, raising the question of whether the first-best outcome can be reached even under imperfect competition in the eco-industry. The main purpose of this paper is to provide a positive answer to this question. We show that the regulator has the opportunity to implement the first-best outcome even if the upstream eco-service market is imperfectly competitive.

One could nevertheless argue that this view invokes a extreme form of delegation. Polluting firms often work in closer (non-market) relation with the eco-indutry based on more or less complex contractual agreements. These situations are clearly out of the scope of this paper. But, in this case, our result also means, from a more policy-oriented point of view, that the regulator may have a strong incentive to design institutions or legal constraint which promote market relations instead of contractual arrangements in order to limit or even to eliminate the policy distortions due to imperfect competition in the ecoindustry.

Our result is mainly driven by the reversal of two assumptions that are made by almost all the papers dealing with upstream imperfect competition and end-of-pipe abatement. Their authors usually first assume that the dirty firm reduces pollution by an amount $A(a)$ - a concave function of the quantity of abatement good $a$ - and second that these goods being produced at a constant marginal cost by the eco-industry. Here, we assume that the polluting firm outsources the decontamination activity, in other words, decides on the amount $A$ of abatement at the current price $p_{A}$ of this service (i.e. bears a constant unit $\operatorname{cost} p_{A}$ ), while the clean-up activity is performed by an upstream firm characterized by convex costs (or, equivalently, a concave abatement function). This assumption reversal fundamentally modifies the polluter's purchasing behavior. For instance if a Pigouvian tax is imposed, he either (i) chooses to pay the tax if the price of the abatement service 
is higher, (ii) decides, in the opposite case, to fully abate the pollution produced at the firm's equilibrium production level, or (iii) is indifferent between the two if the price and the tax are equal. This implies that the demand for eco-services becomes perfectly elastic over a range of quantities which depends on the tax level, so that any monopoly selling these services loses - at least partially - his market power. If the regulator is able to set a tax level such that the monopoly solution belongs to this range of quantities, he clearly destroys upstream monopoly power. He therefore has the opportunity, if the downstream polluting market is competitive, to reach the first-best allocation. Owing to the structure of demand for eco-services, this situation occurs when the monopoly has an incentive to set the highest price at which demand is positive, i.e. the tax level, and to supply, due to marginal cost concerns, a quantity of services lower than required for full pollution abatement. In this situation, the abatement service price equates tax level to marginal cost. If the efficient abatement level does not require full abatement, it remains for the regulator to set the Pigouvian tax equal to optimal marginal damage in order to obtain the first-best outcome.

This paper proceeds as follows. Section 2 gives a presentation of the background literature as related to our question. Section 3 describes the model. Section 4 develops the argument in the simplest setting: homogeneous competitive polluters, an eco-service monopoly and an optimal abatement level that does not require full abatement. In Section 5 we relax several assumptions of this basic case. We show that our result can be extended to (i) include the "boundary" solutions corresponding to full efficient pollution abatement, (ii) take into account regulation by a pollution permit market, (iii) consider polluters who are heterogeneous with regard to their production costs and to their emissions, and (iv) introduce Cournot competition in an eco-industry composed of firms with heterogenous production costs for abatement goods. Concluding remarks are made in Section 6 and technical proofs are relegated to an appendix.

\section{BACKGROUND LITERATURE}

The literature on the EGSS essentially focuses on two topics. Either it examines the incentives provided by environmental policy instruments for the development and the diffusion of new abatement technology (see Requate (2005a) for an overview). Or it explores the consequences of imperfect competition in a mature eco-industry selling abatement goods to a polluting sector (see Sinclair-Desgagné (2008) for a general discussion).

In the first type of literature, not all contributions explicitly consider an EGSS, since this requires innovation to be a private good. Studies often consider an innovative firm investing in $R \& D$ to obtain a patent on a pollution-reducing new technology. Within this framework, taxes and tradeable permits are compared in terms of performance under various settings. Denicolo (1999) and Requate (2005b) make these comparisons under different timing and commitment regimes. A threat of imitation is introduced by Fischer, Parry, and Pizer (2003) while Perino (2008) studies green horizontal innovation, where new technologies reduce pollution of one type while causing a new type of damage. More recently, Perino and Requate (2012) and Bréchet and Meunier (2014) study the relationship between policy stringency and the rate of adoption of an abatement technology. Moreover, most of these papers never introduce imperfect competition in the upstream eco-industry, except Perino (2010) and Sibailly (2013). They address the question of technology adoption when a competitive and polluting industry purchases this abatement technology from a monopolistic upstream industry. 
In contrast, the second type of literature, which is closer to our contribution, takes as given the existence of imperfect competition in the eco-industry and focuses on the provision of abatement goods rather than the adoption of a new technology. The second-best regulation policy is explored under varying instruments. Greaker (2006) and Greaker and Rosendahl (2008) introduce emission standards. Schwartz. and Stahn (2014) explore the case of tradable pollution permits, while Endres and Friehe (2012) examine the impact of environmental liability laws. However, most of the papers introduce a Pigouvian tax, in line with David and Sinclair-Desgagné (2005) and Canton, Soubeyran, and Stahn (2008), the former introducing imperfect competition upstream while the latter studies imperfect competition both upstream and downstream. Both point out that under the assumption of constant marginal damage, if there is perfect competition downstream and upstream Cournot competition, then the second-best Pigouvian tax must be higher than this constant marginal damage. They explain this distortion by the upstream degree of market power. Other papers add industrial organization arguments, like upstream entry (David, Nimubona, and Sinclair-Desgagné, 2011), merger in the eco-industry (Canton, David, and Sinclair-Desgagné, 2012) or R\&D cooperation (Nimubona and Benchekroun, 2015).

Our contribution is also close to Nimubona and Sinclair-Desgagné (2011) who ask the question of the make-or-buy decision. They compare internal abatement effort and external procurement of abatement facilities. But they assume, as in most papers, that this last facility has decreasing returns for the polluting firm, meaning in some sense that the firm outsources the production of a pollution abatement equipment. This excludes the case in which the whole remediation activity is totally outsourced to the eco-industry, which corresponds, in our terminology, to an abatement service, like, waste or wastewater treatment. From that point of view, our emission reduction technology can be viewed as a particular case of the Katsoulacos and Xepapadeas (1995) emission function in which the abatement good has constant returns to scale, a case which to the best of our knowledge, has not been explored. Under this specific assumption we show that a Pigouvian tax reaches the first-best outcome even if the eco-industry is imperfectly competitive since the abatement demand becomes perfectly elastic over a range of quantities. Although the context is somewhat different, both Perino (2008), (Prop. 4) and Perino (2010) (Prop. 5) provide similar results that rely on the emission tax rate (or the price bound in a cap-and-trade scheme) inducing a perfectly elastic demand that also curtails upstream market power by the eco-industry.

\section{A BASIC MODEL OF ENVIRONMENTAL SERVICES}

This section describes the relationship between a polluting industry and an eco-service industry. The main assumptions are spelt out and the first-best allocation is identified.

\subsection{THE MAIN ASSUMPTIONS}

We consider a polluting industry first characterized by a representative price-taking firm and later by firms heterogeneous in both production costs and emissions. The current price of the consumption good is $P_{Q}$, and the production cost associated with an output level, $Q$, is denoted as $c(Q)$. This cost function is assumed twice differentiable, strictly increasing and convex, $c^{\prime}>0, c^{\prime \prime}>0$, inaction is allowed, $c(0)=0$, and the usual boundary conditions are introduced, $c^{\prime}(0)=0$ and $\lim _{Q \rightarrow+\infty} c^{\prime}(Q)=+\infty$. We assume that this activity is polluting, but apply two additional restrictions. First, as is common in the 
eco-industry literature, we assume that the pollution abatement technology is end-of-pipe, meaning that abatements do not modify the production process and therefore do not affect the quantity of pollution imputable to each unit produced. We denote by $\varepsilon(Q)$ the total quantity of pollution. This function is twice differentiable, strictly increasing and convex, $\varepsilon^{\prime}>0, \varepsilon^{\prime \prime}>0$, and satisfies $\varepsilon(0)=0, \varepsilon^{\prime}(0)=0$ and $\lim _{q \rightarrow+\infty} \varepsilon^{\prime}(q)=+\infty$. Secondly, we also assume that these noxious by-products, $\varepsilon(Q)$, can be transferred to an external firm in charge of sanitation. This kind of eco-service includes waste disposal, water treatment, or remediation activities like soil sanitation. Of course, it is always possible that the production process may generate other forms of pollution, like air pollution which are managed by the dirty firm itself, for instance by using specific scrubbers produced by the eco-industry. But for these abatement goods, we are back to the standard literature. For simplicity, we therefore assume that the polluting firm has the opportunity to sell a proportion $A$ of its noxious by-products to a specialized external firm at a given market price $p_{A}$. The remaining pollution is therefore $E(Q, A)=\max \{\varepsilon(Q)-A, 0\}$.

A non-competitive eco-industry carries out the clean-up. This industry is initially characterized by a monopoly, and later by heterogeneous firms in Cournot competition. We implicitly assume that this activity has decreasing returns and requires inputs to be obtained on competitive markets. We can therefore summarize this activity by a cost function $\kappa(A)$ which is twice differentiable, strictly increasing and convex, $\kappa^{\prime}>0, \kappa^{\prime \prime}>0$. We also assume that inaction is possible, $\kappa(0)=0$; however, to ensure that the eco-industry is active, we assume that $\kappa^{\prime}(0)=0 .^{4}$

The environmental damage induced by the remaining emissions $E$ of the polluting sector is measured by a standard damage function $D(E)$. As usual, this function is assumed to be increasing and convex, $D^{\prime}>0$ and $D^{\prime \prime} \geq 0$. We also say that without emissions there is no damage, $D(0)=0$, and assume, for convenience, that there is no marginal damage at a zero-emission level, $D^{\prime}(0)=0$. This last assumption combined with the definition of the remaining emissions ensures that full abatement never occurs at an efficient allocation. ${ }^{5}$ However, it excludes the case of constant marginal damage, that's why we show in Section 4.1 that this restriction is not central to our main argument.

Finally, to close the model, we introduce an inverse demand for the polluting goods $P(Q)$. This function is decreasing, $P^{\prime}<0$, and verifies that $\lim _{Q \rightarrow 0} P(Q)=+\infty$ and $\lim _{Q \rightarrow+\infty} P(Q)=0$.

\subsection{THE FIRST-BEST ALLOCATION}

Under these assumptions, a first-best allocation is given by:

$$
\left(Q^{\text {opt }}, A^{\text {opt }}\right) \in \arg \max _{Q, A \geq 0} \int_{0}^{Q} P(q) d q-c(Q)-D(\max \{\varepsilon(Q)-A, 0\})-\kappa(A)
$$

This is typically a non-smooth optimization problem, but remember that we have assumed that $D(0)=0$ and $D^{\prime}(0)=0$. The condition $D(0)=0$ ensures that the optimal

\footnotetext{
${ }^{4} \mathrm{~A}$ discussion about the emergence of an eco-industry related to the fact that $\kappa^{\prime}(0)>0$ can be found in Canton, Soubeyran, and Stahn (2008).

${ }^{5}$ If the marginal damage at zero is high enough and/or the marginal abatement cost is not too excessive, the end-of-pipe pollution assumption, i.e., $E=\max \{\varepsilon(Q)-A, 0\}$, can lead to an efficient allocation requiring full abatement (see Sans, Schwartz, and Stahn (2017) for a discussion).
} 
level of abatement cannot be greater than emissions because abatement is costly, hence $\varepsilon\left(Q^{\text {opt }}\right)-A^{\text {opt }} \geq 0$, while $D^{\prime}(0)=0$ combined with the positivity of the marginal cost of abatement ensures that this inequality holds strictly. Consequently, the first-best allocation is characterized by the usual first order conditions:

$$
\begin{aligned}
P\left(Q^{o p t}\right)-c^{\prime}\left(Q^{o p t}\right)-D^{\prime}\left(\varepsilon\left(Q^{o p t}\right)-A^{o p t}\right) \times \varepsilon^{\prime}\left(Q^{o p t}\right) & =0 \\
D^{\prime}\left(\varepsilon\left(Q^{o p t}\right)-A^{o p t}\right)-\kappa^{\prime}\left(A^{o p t}\right) & =0
\end{aligned}
$$

Let us now introduce the function $\beta(Q)=\frac{P(Q)-c^{\prime}(Q)}{\varepsilon^{\prime}(Q)}$ defined on $\left[0, Q_{\max }\right]$ where $Q_{\max }$ stands for the optimal level of production without taking into account environmental damage (i.e., $P\left(Q_{\max }\right)=c^{\prime}\left(Q_{\max }\right)$ ). This function measures, for each $Q \leq Q_{\max }$, the marginal benefit from an additional unit of pollution. Therefore an optimal allocation has the property that the marginal benefit of pollution is equal to (i) the marginal damage and (ii) the marginal cost of abating an additional unit of pollution:

$$
\beta\left(Q^{o p t}\right)=D^{\prime}\left(\varepsilon\left(Q^{o p t}\right)-A^{o p t}\right)=\kappa^{\prime}\left(A^{o p t}\right)
$$

For later use, let us also note that this marginal benefit is decreasing and $\beta\left(Q_{\max }\right)=0$ so that $\beta^{-1}:[0,+\infty] \rightarrow\left[0, Q_{\max }\right]$ is defined. This quantity, $\beta(Q)$, can even be viewed as a measure of the distortion induced by an emission tax, $\tau$, between the final good price and the private marginal cost. In fact in a competitive setting in the polluting sector, we must have $\beta(Q)=\tau$.

\section{UPSTREAM MONOPOLY POWER AND THE FIRST-BEST REGULATION}

In order to illustrate our main point in the simplest way, we detail the most straightforward case : a representative polluting firm and an upstream monopoly. Three steps are required to show that a policy maker reaches the efficient allocation with a standard Pigouvian tax scheme. We first compute the inverse demand for abatement services under a downstream market clearing assumption. In the second step, we characterize the behavior of the upstream monopolist whatever the Pigouvian tax. In the last step, we replace the Pigouvian tax by the marginal damage of the first-best emission level and show that the first-best is reached.

\subsection{THE DEMAND FOR ABATEMENT SERVICES}

Since the dirty firm is competitive, we know that its demand for abatement services comes from cost-minimizing behavior which reduces the burden of the environmental constraints. If $\tau$ denotes the Pigouvian tax, the highest cost that this firm is ready to pay conditional on a production level, $Q$, is given by:

$$
C_{A}\left(p_{A}, \tau, Q\right)=\min _{A \geq 0}\left\{p_{A} \times A+\tau \times E(Q, A)\right\}
$$

Bearing in mind that this activity is completely outsourced, meaning that $E(Q, A)=$ $\max \{\varepsilon(Q)-A, 0\}$, an examination of this cost minimization program shows that the conditional demand for abatement services never exceeds $\varepsilon(Q)$ otherwise the firm purchases unnecessary abatement services and that the objective function is linear in $A$ on $[0, \varepsilon(Q)]$. Both properties imply that this conditional demand is either 0 or $\varepsilon(Q)$ when $p_{A}>\tau$ or $p_{A}<\tau$ respectively and any quantity within $[0, \varepsilon(Q)]$ if $p_{A}=\tau$. 
So this optimal tax avoidance strategy leads to a minimal additional operating cost of $C_{A}\left(p_{A}, \tau, Q\right)=\min \left\{p_{A}, \tau\right\} \times \varepsilon(Q)$. The "full production cost" of this firm is therefore given by $c(Q)+C_{A}\left(p_{A}, \tau, Q\right)$. It includes the cost involved in the tax avoidance choice.

However, to move from conditional to real demand for abatement, we also need to know the production level. Since this firm is competitive, its supply simply equates the price of the final good, $p_{Q}$, to this full marginal cost. More precisely, we have:

$$
p_{Q}=c^{\prime}(Q)+\min \left\{p_{A}, \tau\right\} \times \varepsilon^{\prime}(Q)
$$

If we now introduce the market clearing condition for the final good, we can replace $p_{Q}$ by $P(Q)$, and, using the previous definition of $\beta(Q)$, i.e., the marginal benefit of an additional unit of pollution, the preceding equation becomes:

$$
\beta(Q):=\frac{P(Q)-c^{\prime}(Q)}{\varepsilon^{\prime}(Q)}=\min \left\{p_{A}, \tau\right\} \Rightarrow Q\left(p_{A}, \tau\right)=\beta^{-1}\left(\min \left\{p_{A}, \tau\right\}\right)
$$

where $Q\left(p_{A}, \tau\right)$ describes the downstream equilibrium production level for any abatement price and any tax. By using, say, a non-smooth version of Shephard's lemma, we finally deduce the demand for abatement services that the downstream firm outsources at equilibrium. This quantity is of:

$$
A^{d}\left(p_{A}, \tau\right)= \begin{cases}0 & \text { if } p_{A}>\tau \\ {\left[0, \varepsilon\left(\beta^{-1}(\tau)\right)\right]} & \text { if } p_{A}=\tau \\ \varepsilon\left(\beta^{-1}\left(p_{A}\right)\right) & \text { if } p_{A}<\tau\end{cases}
$$

This demand function conveys most of the intuition behind this paper. Since the dirty firm can outsource clean-up at a constant per unit price, there is typically no demand for abatement if the price, $p_{A}$, proposed by the eco-industry is higher than the Pigouvian tax. In the opposite case, the polluter abates the total amount of pollution generated by its activity, $\varepsilon\left(\beta^{-1}\left(p_{A}\right)\right)$. This quantity is endogenous since the downstream equilibrium production level $\beta^{-1}\left(p_{A}\right)$ equates price to full marginal cost and therefore incorporates the abatement price. Finally, if the abatement price is equal to the Pigouvian tax, the polluter becomes indifferent between levels of abatement lower than the emissions generated by the equilibrium production level. This means that the elasticity of the demand becomes infinite at $p_{A}=\tau .^{6}$ The regulator, by controlling this tax rate, is therefore able to create situations resembling perfect competition, and thus, to implement the first-best regulatory solution. However to verify this point, let us first analyze the monopoly provision of environmental services under alternative tax rates.

\subsection{THE MONOPOLY PROVISION OF ENVIRONMENTAL SERVICES}

To construct the monopoly quantity, especially if we plan to introduce Cournot competition, it is more convenient to work with the inverse demand. This is quite easy to define. From Eq. (7), the price never exceeds the Pigouvian tax. In the opposite case, $p(A)=\beta\left(\varepsilon^{-1}(A)\right)$, a decreasing function which becomes zero for $A \geq \varepsilon\left(Q_{\max }\right)$ where

\footnotetext{
${ }^{6}$ One can argue that the firm at $p_{A}=\tau$ can select, even arbitrary, an abatement level in $\left[0, \varepsilon\left(\beta^{-1}(\tau)\right)\right]$. This changes noting to our point. Of course, the demand becomes discontinuous. But this always implies that the elasticity is infinite at $p_{A}=\tau$ since an infinitely small price change (for instance a move from $\tau-\varepsilon$ to $\tau+\varepsilon$ ) induces an non-infinitesimal change in the demand.
} 
$Q_{\max }$ stands for the production level without environmental regulation. This inverse demand is therefore given for all $A \in\left[0, \varepsilon\left(Q_{\max }\right)\right]$ by $\min \{\tau, p(A)\}$ and the monopoly provision of environmental services solves:

$$
\max _{A \in\left[0, \varepsilon\left(Q_{\max }\right)\right]}\{\min \{\tau, p(A)\} \times A-\kappa(A)\}
$$

The existence of a solution is not a real issue here, since we are maximizing a continuous function on a compact set. The inverse demand curve $\min \{\tau, p(A)\}$ nevertheless exhibits a flat part since the dirty firm only reacts to prices lower than the Pigouvian tax. We are therefore dealing with a non-smooth optimization problem leading to several regimes delineated by thresholds which are related to the levels of the Pigouvian tax.

To take the discussion a step further, let us assume - as usual for a monopoly - that the elasticity of $p(A)$ given by $e_{p}(A)=\frac{p^{\prime}(A) A}{p(A)}$ is decreasing and $\lim _{A \rightarrow \varepsilon\left(Q_{\max }\right)} e_{p}(A)$ is larger than $-1 .^{7}$. One implication of this assumption is that the monopoly problem without the upper bound on prices, i.e. with an inverse demand of $p(A)$, has a unique solution. We denote it by $A_{m}$ and by $p\left(A_{m}\right)$ the associated price. Let us now reintegrate the tax constraint on the price.

Figure 1: The monopoly solution for alternative tax rates

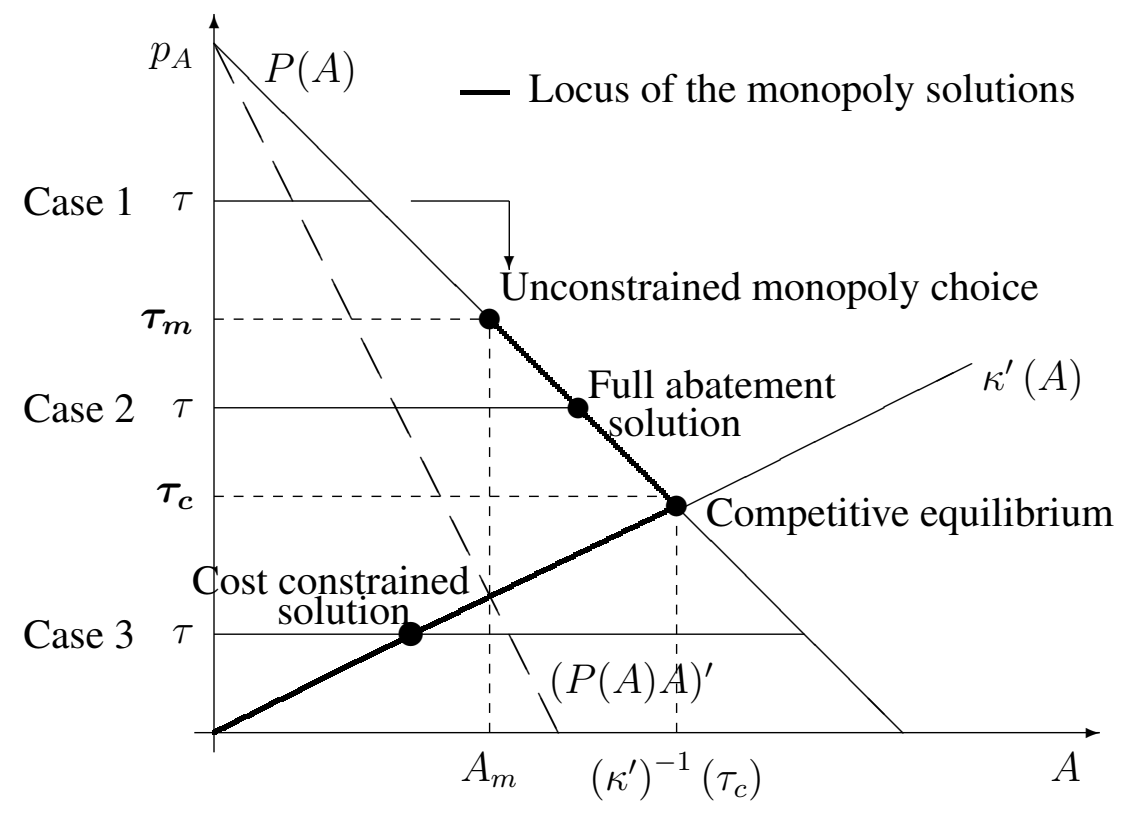

For any tax rate $\tau \geq \tau_{m}=p\left(A_{m}\right)$ (case 1 in Fig. 1), this constraint does not really mater. The monopoly provides $A_{m}$ units of abatement services, i.e $A^{m}(\tau)=A_{m}$. In other words, we end up with full pollution abatement at the monopoly unconstrained price strategy, $P\left(A_{m}\right)$. If the tax rate falls below $\tau_{m}$ (case 2 in Fig 1), the monopoly is no longer able to charge this price without losing the market. It therefore has an incentive to select the highest price $p_{A}=\tau$ and to sell the largest quantity of abatement services

\footnotetext{
${ }^{7}$ Of course, the reader may object that these assumptions are not set on the primary data, especially given that $p(A)=\beta\left(\varepsilon^{-1}(A)\right)$. Other sufficient conditions can be introduced, such as $2 e_{\varepsilon}+e_{\beta^{\prime}}-e_{\varepsilon^{\prime}}>0$ and $e_{\varepsilon}+e_{\beta}>0$, where $e$ denotes the elasticity.
} 
$A_{m}(\tau)=p^{-1}(\tau)$ as long as its marginal production cost is lower than the selling price. There is therefore another threshold $\tau_{c}<\tau_{m}$ at which the behavior of the monopoly changes again and which is given by:

$$
\kappa^{\prime}\left(p^{-1}\left(\tau_{c}\right)\right)=\tau_{c}
$$

Bearing in mind that $p^{-1}(\tau)$ is the quantity that fully abates the downstream equilibrium pollution at price $p_{A}=\tau$, this new threshold, $\tau_{c}$, has two readings. It is obviously the lowest tax rate at which the monopoly has an incentive to charge $p_{A}=\tau$ and to reduce all the downstream pollution. But it is also the competitive price of the abatement services that would prevail if all pollution were reduced. As a consequence, if the tax rate falls below $\tau_{c}$ (case 3 in Fig 1), even if the monopoly quotes the highest possible price $p_{A}=\tau$, it has no incentive to deliver the largest quantity of abatement. In fact, from the earlier definition of the demand curve (see Eq. (7)), we know that for $p_{A}=\tau$ any quantity $A \in\left[0, p^{-1}(\tau)\right]$ belongs to the demand curve because the polluter is indifferent between paying the tax or buying abatement services. This means that it is in the interest of the monopoly to provide abatement services until the price it quotes is equal to its marginal cost, i.e. $A_{m}(\tau)=\left(\kappa^{\prime}\right)^{-1}(\tau)$. But this also means that for tax rates lower than $\tau_{c}$, it behaves like a competitive firm. From this informal discussion, we conclude that:

LEMMA 1 Under our assumptions, (i) the monopoly problem (Eq. 8) has a unique solution for each tax rate, which is given by the continuous function:

$$
A^{m}(\tau)= \begin{cases}\left(\kappa^{\prime}\right)^{-1}(\tau) & \text { if } \tau<\tau_{c} \\ p^{-1}(\tau)=\varepsilon\left(\beta^{-1}(\tau)\right) & \text { if } \tau \in\left[\tau_{c}, \tau_{m}\right] \\ A_{m}=p^{-1}\left(\tau_{m}\right)=\varepsilon\left(\beta^{-1}\left(\tau_{m}\right)\right) & \text { if } \tau>\tau_{m}\end{cases}
$$

(ii) the price of these services is $P_{A}^{m}(\tau)=\min \left\{\tau, \tau_{m}\right\}$, and (iii) from Eq. (6), the equilibrium production of the dirty good is:

$$
Q^{m}(\tau)=\beta^{-1}\left(\min \left\{\tau, \tau_{m}\right\}\right)
$$

\subsection{THE EFFICIENT REGULATION OF EMISSIONS}

With the previous lemma, the die is cast. If the first-best Pigouvian tax, $\tau^{\text {opt }}$, which corresponds to the marginal damage of the first-best pollution level, i.e. $D^{\prime}\left(\varepsilon\left(Q^{o p t}\right)-A^{o p t}\right)$, is lower than $\tau^{c}$, the regulator is able to implement the first-best allocation, since the downstream market is competitive and the monopoly behaves like a pure competitor. By lemma 1, we have:

$$
\forall \tau<\tau_{c}, \quad P_{A}^{m}(\tau)=\kappa^{\prime}\left(A^{m}(\tau)\right)
$$

It simply remains to ensure that $\tau^{\text {opt }}<\tau_{c}$. So let us assume the contrary. Since at the firstbest (see Eq. (3)), $\tau^{o p t}=\beta\left(Q^{o p t}\right.$ ) and $\beta$ decreasing, we can first claim that the emissions before abatement are lower at the first-best than those generated by the monopoly outcome at a tax rate $\tau=\tau_{c}$. More precisely:

$$
\tau^{o p t} \geq \tau_{c} \Leftrightarrow \underbrace{\varepsilon\left(Q^{o p t}\right)=\varepsilon\left(\beta^{-1}\left(\tau^{o p t}\right)\right)}_{\text {from Eq. (3) }} \leq \underbrace{\varepsilon\left(\beta^{-1}\left(\tau_{c}\right)\right)=\varepsilon\left(Q^{m}\left(\tau_{c}\right)\right)}_{\text {from Eq. (11) }}
$$


Secondly, if $\tau^{\text {opt }} \geq \tau_{c}$, we can also say, from the definition of $\tau_{c}$ (see Eq. (9)), that the firstbest abatement level is larger than the abatement required to fully reduce the emissions generated by the monopoly equilibrium for $\tau=\tau_{c}$. In fact:

$$
\tau^{o p t} \geq \tau_{c} \Leftrightarrow \underbrace{A^{o p t}=\left(\kappa^{\prime}\right)^{-1}\left(\tau^{o p t}\right)}_{\text {from Eq. (3) }} \geq \underbrace{p^{-1}\left(\tau_{c}\right)=\varepsilon\left(\beta^{-1}\left(\tau_{c}\right)\right)=\varepsilon\left(Q^{m}\left(\tau_{c}\right)\right)}_{\text {from Eqs.(9).and.(10) }}
$$

Both observations imply that the optimal abatement level is higher than the amount of pollution generated by the optimal production level, i.e. $A^{\text {opt }} \geq \varepsilon\left(Q^{o p t}\right)$. But we have assumed that $D^{\prime}(0)=0$, so we know from our early discussion of the optimal outcome (Section 3.2) that $A^{\text {opt }}<\varepsilon\left(Q^{\text {opt }}\right)$. From this contradiction, we can therefore say:

PROPOSITION 2 Even if an upstream monopoly controls the price of the environmental services while the downstream commodity market remains competitive, the regulator reaches the first-best outcome by setting the Pigouvian tax at the marginal damage of the emissions (evaluated at the first-best), i.e., by setting $\tau^{\text {opt }}=D^{\prime}\left(\varepsilon\left(Q^{\text {opt }}\right)-A^{\text {opt }}\right)$.

The reader may perhaps object that it is too restrictive to say that there is no marginal damage at a zero-emission level. This assumption, for instance, excludes the case of constant marginal damage. The next section gives several extensions and relaxes this restriction.

\section{SOME EXTENSIONS}

Our first extension deals with the above-mentioned issue. But, we can also examine whether the result holds when the regulator uses a different incentive-based mechanism, such as tradeable pollution permits. The answer is again yes, as long as this new market is competitive. We then relax the representative polluting firm assumption by introducing heterogeneous dirty firms both in terms of their production costs and their emissions. We finally consider the case of upstream Cournot competition between heterogeneous ecoservice providers.

\subsection{EFFICIENT REGULATION AND FULL ABATEMENT}

To illustrate this point, let us return to the construction of the efficient outcome and relax $D^{\prime}(0)=0$. This outcome solves the optimization program (Eq. (1)) introduced in Section 3.2. But if we only assume that $D(0)=0$, we can only argue that $\varepsilon(Q)-A \geq 0$, (i.e., without strict inequality). The interior first-order optimality conditions given by Eqs. (2a) and ( $2 b$ ) must therefore be amended. If $\lambda$ denotes the Lagrangian multiplier associated with this full abatement constraint, the new FOCs become:

$$
\left\{\begin{array}{l}
P\left(Q^{o p t}\right)-c^{\prime}\left(Q^{o p t}\right)-\left(D^{\prime}\left(\varepsilon\left(Q^{o p t}\right)-A^{o p t}\right)-\lambda\right) \varepsilon^{\prime}\left(Q^{o p t}\right)=0 \\
D^{\prime}\left(\varepsilon\left(Q^{o p t}\right)-A^{o p t}\right)-\kappa^{\prime}\left(A^{o p t}\right)-\lambda=0 \\
\lambda\left(\varepsilon\left(Q^{o p t}\right)-A^{o p t}\right)=0 \text { and } \lambda \geq 0
\end{array}\right.
$$

If this constraint is not binding, we are back, of course, to the case of partial abatement situation analyzed above. So let us concentrate on the case in which $\lambda>0$, meaning that there is full abatement since $\varepsilon\left(Q^{o p t}\right)=A^{o p t}$. In this situation, the first and second equations of system (15) suggest that, for an efficient allocation, the marginal benefit $\beta\left(Q^{o p t}\right)$ of an additional unit of pollution must be equal to the marginal abatement cost. 
But to achieve full abatement, this marginal benefit only needs to be smaller than the marginal damage from the first unit of pollution. This situation essentially occurs if $D^{\prime}(0)$ is high enough. In this case, the efficient allocation verifies:

$$
\begin{aligned}
& E^{o p t}=\varepsilon\left(Q^{o p t}\right)-A^{o p t}=0 \\
& \beta\left(Q^{o p t}\right)=\kappa^{\prime}\left(A^{o p t}\right)<D^{\prime}(0)
\end{aligned}
$$

instead of the interior condition introduced in Eq. (3).

Let us now return to the monopoly case. Since marginal damage is not part of the definition of the different behaviors, the monopoly outcome depicted in Lemma 1 remains unchanged. So, if we want to extend our result, we simply need to set a tax rate such that the monopoly outcome at this tax rate satisfies conditions (16a) and (16b). Let us take $\tau=\tau^{c}$. From Lemma 1, the equilibrium abatement and production levels are $A^{m}\left(\tau_{c}\right)=\varepsilon\left(\beta^{-1}\left(\tau_{c}\right)\right)$ and $Q^{m}\left(\tau_{c}\right)=\beta^{-1}\left(\tau_{c}\right)$, so that condition (16a) is immediately satisfied. Moreover since $\tau_{c}$ verifies $\tau_{c}=\kappa^{\prime}\left(\varepsilon\left(\beta^{-1}\left(\tau_{c}\right)\right)\right)$, we also have that $\beta\left(Q^{m}\left(\tau_{c}\right)\right)=\kappa^{\prime}\left(A^{m}\left(\tau_{c}\right)\right)$. It should, however, be noted that in order to obtain a first-best outcome requiring full abatement, the tax rate needs to be strictly lower than the marginal damage, i.e. $\tau_{c}<D^{\prime}(0)$. The intuition behind this last observation directly follows from Lemma 1: if the tax rate is higher than $\tau_{c}$, the monopoly outcome induces full pollution abatement but at a lower level of production of both final goods and abatement services. We can therefore state that:

PROPOSITION 3 Assume that the marginal damage of the first unit of pollution is high enough for full abatement to become the efficient outcome. If the regulator sets the Pigouvian tax at $\tau^{\text {opt }}=\tau_{c}$ given by Eq. (9), he again obtains the first-best outcome. Moreover this tax rate $\tau_{c}$ is, in this case, lower than the marginal damage.

\subsection{POLLUTION PERMIT MARKET}

Let us now verify that our result also holds if the regulator implements a pollution permit market instead of a Pigouvian tax. To illustrate this point, let us return to the case depicted in Section 3 and introduce a competitive market of pollution permits. The regulator sets the pollution cap $\bar{E}$. Without loss of generality we assume that pollution permits are sold at auction. ${ }^{8}$ One permit corresponds to one unit of emission and the competitive price of these permits is denoted by $p_{E}$.

The introduction of pollution rights requires that the dirty competitive firm purchases a quantity of rights which covers its residual pollution (i.e. after abatement). This firm must therefore foresee, for each permit price given by $p_{E}$, the quantity of abatement services delivered by the non-competitive eco-industry in order to fix its own permit purchasing behavior. ${ }^{9}$ In this case, one usually expects that the shape of the demand for rights integrates the under-provision of abatement goods due to imperfect competition in the eco-

\footnotetext{
${ }^{8}$ For simplicity, we do not explicitly introduce the initial distribution of pollution permits. Under a "grandfathering" system, firms own initial pollution right endowments and express a net demand for rights. But under pure competition on the permit market, we know from Montgomery (1972), that selling or freely distributing lead to the same result.

${ }^{9}$ This assumption is typically based on a backward solution of a dynamic game with the following timing: (i) the permit market clears (ii) abatement goods are traded and (iii) production and emissions take place.
} 
industry and that the first-best becomes out of reach even if the polluting sector is perfectly competitive. This is true for abatement good and corresponds to the situation studied by Schwartz. and Stahn (2014). But this result is again different when we consider abatement services.

To get the intuition, let us try to construct the demand for pollution rights by looking at the residual pollution for each permit price, $p_{E}$. This requires the construction, for each $p_{E}$, of the effective production level of the dirty firm and of the equilibrium abatement services supplied by the eco-industry. But the permit market price is, under perfect competition on this market, taken as given by all actors and works, at this stage of the argument, like a Pigouvian $\operatorname{tax} \tau$. This means, at least from a formal point of view, that the results obtained in Section 3 concerning the inverse demand and the supply of abatement services by the monopoly extend to this case: it simply remains to replace the Pigouvian $\operatorname{tax} \tau$ by the price $p_{E}$ of the emission rights. If we go back to Lemma 1 the quantities $A^{m}\left(p_{E}\right)$ and $Q^{m}\left(p_{E}\right)$ in Eqs. (10) and (11) now turn out to be the equilibrium abatement and production levels conditionally to the price $p_{E}$ of a pollution right. From these definitions, we can say that the demand for pollution permits is given by:

$$
E^{D}\left(p_{E}\right)=\left\{\begin{array}{l}
\varepsilon\left(\beta^{-1}\left(p_{E}\right)\right)-\left(\kappa^{\prime}\right)^{-1}\left(p_{E}\right) \text { if } p_{E}<\tau_{c} \\
0 \text { if } p_{E} \geq \tau_{c}
\end{array}\right.
$$

It is now important to observe that the demand for rights of the polluting firm is positive only if the clean-up monopoly is, at the price $p_{E}$, constrained by its marginal cost (see Fig 1 and its interpretation). But, in this case, the quantity choice of the monopoly is like the one of a pure competitor. There is therefore some hope to maintain our result.

To verify this point, let us now assume the pollution cap chosen by the regulator is the first-best pollution level $\bar{E}=\varepsilon\left(Q^{\text {opt }}\right)-A^{\text {opt }}>0$, (meaning that we implicitly assume that $\left.D^{\prime}(0)=0\right)$ and let us construct $p_{E}^{*}=D^{\prime}\left(\varepsilon\left(Q^{o p t}\right)-A^{o p t}\right)$, a quantity which is known to be lower than $\tau_{c}$ (see our discussion in Section 4.3). If we now construct $E^{D}\left(p_{E}^{*}\right)$, Eq (3) tells us that $\beta^{-1}\left(p_{E}^{*}\right)=Q^{o p t}$ and $\left(\kappa^{\prime}\right)^{-1}\left(p_{E}^{*}\right)=A^{\text {opt }}$ meaning that the permit market clears at $p_{E}^{*}$, for a pollution cap equal to the first-best pollution level, i.e. $E^{D}\left(p_{E}^{*}\right)=\bar{E}$. We even observe that the demand for pollution rights is decreasing for all $p_{E}<\tau_{c}$ :

$$
\frac{d E^{D}\left(p_{E}\right)}{d p_{E}}=\frac{\varepsilon^{\prime}\left(\beta^{-1}\left(p_{E}\right)\right)}{\beta^{\prime}\left(\beta^{-1}\left(p_{E}\right)\right)}-\left(\kappa^{\prime \prime}\left(\left(\kappa^{\prime}\right)^{-1}\left(p_{E}\right)\right)\right)^{-1}<0
$$

since, under our assumptions, $\kappa^{\prime \prime}, \varepsilon^{\prime}>0$ and $\beta^{\prime}<0$. This implies that the price $p_{E}^{*}$ is the unique equilibrium of the permit market when the pollution cap is $\bar{E}$. Finally, since $p_{E}^{*}=\tau^{o p t}$, i.e. the optimal Pigouvian tax which implements the first-best (see Section 4.3 ), the regulator knows for sure by selling an amount of permits, $\bar{E}$, that he implements the first-best allocation.

However, it should be noted that this argument only partially extends to the case where $D^{\prime}(0)>0$. It only works if the full abatement constraint (see Eq. (15)) is not binding at the first-best. ${ }^{10}$ If full abatement is required, there is no point in organizing a pollution permit market because there is nothing to trade. To conclude this discussion, we can therefore

\footnotetext{
${ }^{10}$ In fact, from our discussion in Section 5.1, we can say that the full abatement constraint is not binding (even weakly) if $D^{\prime}(0)>\tau_{c}$.
} 
say:

PROPOSITION 4 If pollution is regulated by a pollution permit market, the regulator also achieves an efficient allocation by choosing the optimal pollution cap given by $\bar{E}=$ $\varepsilon\left(Q^{o p t}\right)-A^{\text {opt }}$. This however requires that $\bar{E}>0$.

It must however be noticed that we have assumed that the upstream monopoly does not try to anticipate the effect of its own strategic choice, i.e. the abatement price, on the permit market equilibrium price. In other words, we have implicitly considered a timing of the game in which (a) the permit market clears, (b) the abatement price is chosen and (c) the final production and emissions take place. By moving to a timing given by (b) followed by (a) and (c) as suggested, in a different context, by Perino (2010), new strategic manipulations appear, in particular, the upstream monopolist will be able to change the "flat part" of its demand curve. This clearly limits our previous result.

\subsection{HETEROGENEOUS POLLUTERS}

It is also interesting to see whether this result extends to heterogeneous polluters. Let us introduce $m$ polluting firms, indexed by $j$, with different cost and emission functions, $c_{j}(q)$ and $\varepsilon_{j}(q)$, each of them satisfying the assumptions in Section 3.1. All the other assumptions are maintained, especially those concerning the marginal damage at 0 , so that an efficient allocation is now given by:

$$
\begin{aligned}
& \forall j \quad P\left(\sum_{j=1}^{m} q_{j}^{o p t}\right)-c_{j}^{\prime}\left(q_{j}^{o p t}\right)-D^{\prime}\left(\sum_{j=1}^{m} \varepsilon_{j}\left(q_{j}^{o p t}\right)-A^{o p t}\right) \cdot \varepsilon_{j}^{\prime}\left(q_{j}^{o p t}\right)=0 \\
& D^{\prime}\left(\sum_{j=1}^{m} \varepsilon_{j}\left(q_{j}^{o p t}\right)-A^{o p t}\right)-\kappa^{\prime}\left(A^{o p t}\right)=0
\end{aligned}
$$

Let us now turn to the market outcome. The intuition behind this extension is quite simple. Even if the polluting firms are heterogeneous in costs and emissions, they invariably choose their level of abatement by comparing the price $p_{A}$ with the Pigouvian $\operatorname{tax} \tau$. We can therefore expect the aggregate demand for abatement goods to behave in the same way: no abatement if $p_{A}>\tau$, full abatement denoted $A_{f}\left(p_{A}\right)$ if $p_{A}<\tau$ and any situation between the two if $p_{A}=\tau$. Moreover, if the demand on the domain corresponding to full abatement is still decreasing and bounded from above, the inverse demand has the same structure as that obtained in Section 4.1. So, with similar assumptions on its elasticity, the properties of the monopoly outcome provided in Lemma 1 should extend to the case of heterogeneous polluters.

The main weakness of this argument is that computing the aggregate level of abatement corresponding to full pollution reduction $\left(A_{f}\left(p_{A}\right)\right)$ and, more generally, constructing the market-clearing production levels for all $\tau$ and $p_{A}$, now become an intricate operation. In fact - as in Section 4.1 - it is easy to compute the individual conditional demand for abatement services and the cost function related to this activity. But to compute the marketclearing production level, we now face a system of $m$ equations, since for each firm, the price of the polluting good is equal to the full marginal cost including abatement cost. In other words, these individual production levels solve:

$$
\forall j=1, \ldots, m \quad P\left(\sum_{j=1}^{m} q_{j}\right)=c_{j}^{\prime}\left(q_{j}\right)+\min \left\{p_{A}, \tau\right\} \times \varepsilon_{j}^{\prime}\left(q_{j}\right)
$$

instead of the single equation given by Eq. (6). Nevertheless, it can be shown that: 
LEMMA 5 Under our assumptions on demand, costs and emissions, the system of Eqs. (20) admits a unique solution $\left(q_{j}\left(\min \left\{p_{A}, \tau\right\}\right)\right)_{j=1}^{m}$. Moreover, $A_{f}\left(p_{A}\right)=\sum_{j=1}^{m} \varepsilon_{j}\left(q_{j}\left(p_{A}\right)\right)$ - the total quantity of abatement good which induces full pollution reduction - is decreasing (for all $\left.p_{A} \leq \tau\right)$ and bounded from above by $A_{\max }=\sum_{j=1}^{m} \varepsilon_{j}\left(q_{j}(0)\right)$.

It finally remains to verify that the Pigouvian tax $\tau^{o p t}=D^{\prime}\left(\sum_{j=1}^{m} \varepsilon_{j}\left(q_{j}^{o p t}\right)-A^{o p t}\right)$ (i) can achieve the first-best outcome and (ii) is lower than the highest tax, now given by $\tau_{c}^{\prime}=\kappa^{\prime}\left(A_{f}\left(\tau_{c}^{\prime}\right)\right),{ }^{11}$ that induces competitive behavior by the abatement producer. If the second point is satisfied, the first one is easily obtained by identification. In fact, if $\tau^{o p t}<\tau_{c}^{\prime}$, the eco-service firm equates its marginal cost to the Pigouvian tax, i.e., $\tau^{\text {opt }}=\kappa^{\prime}(A)$, so that condition (19b) is satisfied. Moreover, since in this case the price of the abatement good is $\tau^{o p t}$, it follows that the set of Eqs (20), describing the equilibrium production levels, corresponds exactly to the efficiency conditions given by Eqs. (19a). It remains to verify that $\tau^{o p t}<\tau_{c}^{\prime}$. The argument works as in Section 4.3. If $\tau^{\text {opt }} \geq \tau_{c}^{\prime}$, we can now claim by the definition of $\tau_{c}^{\prime}$ and by $A_{f}^{\prime}\left(p_{A}\right) \leq 0$, that abatement activity still exceeds the total amount of emissions, i.e. $\left(\kappa^{\prime}\right)^{-1}\left(\tau^{\text {opt }}\right) \geq \sum_{j=1}^{m} \varepsilon_{j}\left(q_{j}\left(\tau^{\text {opt }}\right)\right)$. Seeing that these quantities are the efficient ones, this rules out the residual pollution implied by the assumption that $D^{\prime}(0)=0 .{ }^{12}$ We can therefore state that:

PROPOSITION 6 Even if the polluting sector is composed of firms heterogeneous in costs and emissions, the regulator can neutralize the monopoly power on the abatement service market and obtain the first-best solution by setting the tax rate at the marginal damage evaluated at the first-best.

At that point, let us again emphasize that our results requires perfect competition in the downstream polluting industry. Adding a new market imperfection induces a second-best choice of the tax rate. If one refers for instance to Canton, Soubeyran, and Stahn (2008) who consider the case of upstream and downstream Cournot competition, one can expect that, in the case of environmental services, the optimal tax rate will be lower than the marginal damage since, loosely speaking, the elasticity of the inverse abatement demand is zero at the optimal tax rate.

\subsection{COURNOT COMPETITION IN THE ECO-INDUSTRY}

Let us now restore the representative polluting firm assumption, and consider the case of upstream Cournot competition by introducing $n$ heterogeneous firms, indexed by $i$, into the eco-industry, each characterized by a specific cost function $\kappa_{i}(a)$. Given that all the other assumptions are maintained, an efficient allocation now verifies:

$$
\forall i=1 \ldots, n \quad \beta\left(Q^{o p t}\right)=D^{\prime}\left(\varepsilon\left(Q^{o p t}\right)-\sum_{i=1}^{n} a_{i}^{o p t}\right)=\kappa_{i}^{\prime}\left(a_{i}^{o p t}\right)
$$

\footnotetext{
${ }^{11}$ By a similar argument to that in the proof of Lemma 1, it can be shown that $\tau_{c}^{\prime}$ exists and is unique.

${ }^{12}$ This argument can, as in Section 5.1, be extended to the case $D^{\prime}(0)>0$. The computation of the firstbest is nevertheless more tedious. Due to downstream heterogeneity in emissions, some firms abate all their emissions while others not. By in any case the result is obtained by setting $\tau=\tau_{c}^{\prime}$.
} 
Does a Pigouvian tax of $\tau^{o p t}=D^{\prime}\left(\varepsilon\left(Q^{o p t}\right)-\sum_{i=1}^{n} a^{o p t}\right)$ still lead to the first-best allocation?

The answer to this question is not necessary obvious. To get the intuition, remember that the behavior of the upstream monopoly, and, in this case the market outcome, was described by a piecewise continuous function (see Lemma 1). This kind of function, at least intuitively, now describes the best response of each oligopolist and, as a best response, is related to the choice of the other players in a more or less complex way. This means that the market outcome, i.e. the Nash equilibrium, can be, for a given tax rate, a rather intricate object. In this paper, we do not study the relation between the Pigouvian tax and the Nash equilibrium. We simply characterize, in a first step, the best responses and even restrict our attention to a subset of tax rates on which these best responses look like the monopoly behavior described in Section 4.2. In a second step, we show, by using the properties of these reaction functions, that a vector of strategies characterized by the equality between the marginal cost and the tax rate for each firm is the unique Nash equilibrium. We finally make sure that $\tau^{\text {opt }}$ belongs to the set of tax to which we are restricted our attention meaning that we have at $\tau^{o p t}$ a competitive equilibrium, hence the first-best.

Let us first examine the best responses of these Cournot players, since the behavior of the polluting firm remains unchanged by construction (see Section 4.1). If we denote by $A_{-i}=\sum_{j=1, j \neq i}^{n} a_{j}^{o p t}$ the aggregated abatement supply of the opponents, the best response of Firm $i$ is given by:

$$
B R_{i}\left(A_{-i}, \tau\right) \in \arg \max _{a_{i}}\left\{\min \left\{\tau, p\left(a_{i}+A_{-i}\right)\right\} \times a_{i}-\kappa_{i}\left(a_{i}\right)\right\}
$$

where $p(A)=\beta\left(\varepsilon^{-1}(A)\right)$ stands, as usual, for the inverse demand corresponding to full abatement behavior by the polluting firm.

The main difference here from the monopoly case stems from the fact that the different kinds of behaviors identified in Lemma 1 now depend, at a given tax rate, on the behavior of the other players. First, it is quite obvious that a firm is now able to exert its full market power only if its best response against the choices of the others, $A_{-i}$, is such that the price remains lower than the tax rate. In other words, if we denote by $b r_{i}\left(A_{-i}\right)$ the best response of $i$ when the price is not bounded by the tax rate, we can identify a first threshold $A_{-i}^{m}(\tau)$ implicitly given by:

$$
p\left(b r\left(A_{-i}^{m}(\tau)\right)+A_{-i}^{m}(\tau)\right)=\tau
$$

and if $A_{-i} \geq A_{-i}^{m}(\tau)$, we can say that Firm $i$ exerts full market power and plays $B R_{i}\left(A_{-i}, \tau\right)=$ $b r_{i}\left(A_{-i}\right)$. Now let us assume that $A_{-i}$ falls below $A_{-i}^{m}(\tau)$. In this case Firm $i$ cannot reach its best solution, since the upper bound on price matters. As in the monopoly case, but now given the strategies of the others, Firm $i$ provides the largest quantity of services at the highest price, $\tau$. In other words, it sells $B R_{i}\left(A_{-i}, \tau\right)=p^{-1}(\tau)-A_{-i}$. But as $A_{-i}$ decreases, Firm $i$ 's production increases. It can therefore, as in the monopoly case, end up with its own marginal production cost being higher than the constant price $\tau$. This gives us the opportunity to identify a second threshold $A_{-i}^{c}(\tau)$ given by:

$$
\kappa_{i}^{\prime}\left(p^{-1}(\tau)-A_{-i}^{c}(\tau)\right)=\tau \Leftrightarrow A_{-i}^{c}(\tau)=p^{-1}(\tau)-\left(\kappa_{i}^{\prime}\right)^{-1}(\tau)
$$

such that for $A_{-i}<A_{-i}^{c}(\tau)$, Firm $i$ behaves like a pure competitor by equating its marginal cost to the market price. 
Of course, this informal argument only works if both thresholds, $A_{-i}^{c}(\tau)<A_{-i}^{m}(\tau)$, are strictly positive, otherwise some of these cases are vacuous. A formal construction of the best response is provided in the appendix. We even show that these three situations only occur when the rate $\tau$ is lower than $\tau_{c}^{i}$ given by $\tau_{c}^{i}=\kappa_{i}^{\prime}\left(p^{-1}\left(\tau_{c}^{i}\right)\right)$. But, since we are concerned purely with situations in which eco-industry competitive behaviors arise, we only spell out the characterization of the best response for $\tau \leq \tau_{c}^{i}$.

LEMMA 7 Under the assumption on the elasticity of $p(A)$ introduced in Section 4.2, the best response of an eco-service firm, for any tax rate $\tau<\tau_{c}^{i}$ and any $A_{-i} \in\left[0, \varepsilon^{-1}\left(Q_{\max }\right)\right]$, is given by:

$$
B R\left(A_{-i}, \tau\right)=\left\{\begin{array}{l}
\left(\kappa_{i}^{\prime}\right)^{-1}(\tau) \text { if } A_{-i}<A_{-i}^{c}(\tau) \\
p^{-1}(\tau)-A_{-i} \text { if } A_{-i}^{c}(\tau) \leq A_{-i} \leq A_{-i}^{m}(\tau) \\
b r_{i}\left(A_{-i}\right) \text { if } A_{-i} \geq A_{-i}^{m}(\tau)
\end{array}\right.
$$

Moreover, this best response is continuous and non-increasing with $A_{-i}$.

This last lemma also tells us that competitive behavior is part of abater $i^{\prime}$ s best response only if the tax rate is lower than $\tau_{c}^{i}$. So let us concentrate in the rest of the argument on taxes lower than $\tau_{c}^{\min }=\min _{i=1, \ldots, n}\left\{\tau_{c}^{i}\right\}$ so that the best response of each player incorporates competition. In this case, it can be shown that:

LEMma 8 For any tax $\tau<\tau_{c}^{\min }$, the unique Cournot equilibrium leads, for each firm, to a supply of eco-services of $a_{i}^{C}(\tau)=\left(\kappa_{i}^{\prime}\right)^{-1}(\tau)$, while the price of these services is $P_{A}^{C}(\tau)=\tau$. From Eq. (6), we observe that the production of the dirty good is $Q^{C}(\tau)=$ $\beta^{-1}(\tau)$.

In other words, for any $\tau<\tau_{c}^{\min }$ and even if there is Cournot competition in the ecoindustry, the unique equilibrium is such that the firms in the eco-industry behave like pure competitors by equating their marginal cost to the price of the abatement services. Thus, to confirm that the regulator is able to implement the first-best, we need to verify that the first-best tax rate $\tau^{o p t}=D^{\prime}\left(\varepsilon\left(Q^{o p t}\right)-\sum_{i=1}^{n} a_{i}^{o p t}\right)$ is lower than $\tau_{c}^{\text {min }}$. If this is not the case, there exists at least one agent, say $i_{0}$, for which $\tau^{o p t}>\kappa_{i_{0}}^{\prime}\left(p^{-1}\left(\tau^{o p t}\right)\right)$. But this implies, for our characterization of an optimal allocation (Eq. (21)), that:

$$
a_{i_{0}}^{o p t}=\left(\kappa_{i_{0}}^{\prime}\right)^{-1}\left(\tau^{o p t}\right)>p^{-1}\left(\tau^{o p t}\right)=\varepsilon\left(\beta^{-1}\left(\tau^{o p t}\right)\right)=\varepsilon\left(Q^{o p t}\right)
$$

so that $\sum_{i=1}^{n} a_{i_{0}}^{\text {opt }}>\varepsilon\left(Q^{\text {opt }}\right)$, since all the $a_{i}^{\text {opt }} \geq 0$. In other words there is, at the optimum, more abatement than emissions, which is a contradiction. We can therefore say:

PROPOSITION 9 If there is Cournot competition in an eco-service industry and pure competition in the polluting sector, the first-best allocation can be reached by setting the tax rate to the marginal damage.

\section{CONCLUDING REMARKS}

The EGSS is highly concentrated and the economic literature has so far mainly analyzed how this feature impacts the design of environmental regulations. However, no study has yet analyzed the extent to which distinguishing between abatement goods and abatement services matters for environmental regulation. By an abatement service, we 
mean an activity which is totally outsourced by the polluting firm to a specialized firm and is purchased on a market at a given price per unit of abatement. By contrast, what we term an abatement good is used directly by the polluting firm. This distinction is of particular interest for policy makers. There are two market failures in our economy: market power on the abatement service market and pollution generated by downstream firms. Yet our results suggest that the regulator can reach the first-best outcome with only one tool: environmental regulation.

The main intuition behind our results is based on the idea that a polluter, when he outsources abatement services, only makes a trade-off between the price of this service and the compliance cost with an environmental policy. In other words, he does not care about the way the pollution is reduced by the eco-service firm. This simple observation drastically modifies his purchasing behavior. In fact, we have shown that the demand for abatement becomes infinitely elastic over a certain range. This at least partially offsets upstream market power, meaning that if the Pigouvian tax is set at the right level, the monopoly will choose the first-best level of production. We explored this argument in the context of a downstream representative polluting firm and an upstream monopoly. We then extended our model to check the robustness of the result. We first set assumptions, such as total abatement is possible. We secondly considered a pollution permit market instead the Pigouvian tax, and thirdly, introduced heterogenous polluters. Finally we extended our results to upstream Cournot competition between heterogenous abaters.

Our findings nevertheless have several limitations. In this paper, we essentially explore the case of upstream market power. However, if we add other market failures, modify the behavior of the upstream abater or relax the benevolent regulator assumption, the results clearly change.

Concerning market failures, it is first obvious that the introduction of downstream imperfect competition between polluters challenges our results. In this case the regulator, even if he is able to restore upstream perfect competition, can be expected to have an incentive to lower the Pigouvian tax to below its first-best level in order to limit the reduction in production of the final good induced by this additional market failure. Secondly, if a pollution permit market is organized, a polluting firm may exert a dominant position, i.e., a simple manipulation (see Hahn (1984) and Westskog (1996)) or by manipulating the costs of its opponents on the output market, i.e. an exclusionary manipulation (see Misiolek and Elder (1989), Sartzetakis (1997) or Von der Fehr (1993)). Thirdly, it could also happen that the upstream eco-industry firm emits some pollution during the abatement process. If it is an other kind of pollutant subject to a specific regulation our result is maintained. But if this one is simply a residue of the initial dirty by-product, our result would probably be changed.

Our results largely rely on the assumption that the upstream eco-firms propose linear price contracts on an anonymous spot market and behaves without any capacity constraint. If the abater has the option of proposing non-linear price schedules, for instance, he will be able to "smooth" the polluter tax avoidance strategy. Nevertheless, if the contract between the downstream polluter and the upstream abater shares the returns obtained by the joined profit maximization, one can expect, if the polluting good market is competitive, that the pollution can be regulated efficiently. Additional imperfections must be introduced like asymmetric information.

Now let us consider limited abatement capacities. For exemple, incinerators face capacity constraints. In order to take into account this assumption, two cases should be analysed 
depending whenever this constraint is binding or not at first best. If not, our result surely extends since this additional constraint only modifies the behavior of our model out of equilibrium (including the regulator choice). In the other case, one has also to take care at the change induced on the first best conditions. We nevertheless guess that our result is maintained since this one is mainly driven by the behavior of the demand for abatement goods. This should however be verified.

In this paper, we also restrict our attention to a benevolent and perfectly informed regulator controlling a closed economy. Moreover, lobbies are recognized to influence the definition of environmental policy (Aidt, 1998), and abatement services are often exchanged on an international market. Canton (2008) studies the role of lobbies in the case of an eco-industry providing environmental goods. Moreover, in an open economy, each firm is subject to national environmental regulations. In this case, environmental policies can be used in a strategic way (see for instance Barrett (1994) or Hamilton and Requate (2004)). Nimubona (2012) studies the effect on the eco-industry sector of reductions in trade barriers that were agreed in the Doha Round of the WTO and Goeschl and Perino (2017) considers the effect of market power in the eco-industry on the stringency and stability of international environmental agreements. As most of the paper in this literature, we introduced a perfectly informed regulator. It is obvious the perfect information issue plays an important role. Without this assumption, our first-best result cannot be reached.

Further research could usefully investigate whether taking into account these additional features would challenge or alter our results.

\section{APPENDIX A: PROOF OF LEMMA 1}

We need to solve:

$$
\max _{A \in\left[0, \varepsilon\left(Q_{\max }\right)\right]}[\underbrace{\min \{\tau, p(A)\} A-\kappa(A)]}_{\pi(A, \tau)} \text { where } p(A)=\beta\left(\varepsilon^{-1}(A)\right)
$$

Step 1: Existence of a unique solution

Since we maximize $\pi(A, \tau)$ over a compact set, it remains to verify that $\pi(A, \tau)$ is strictly concave in $A$. Moreover, $\kappa(A)$ being strictly convex, it remains to check that $\min \{\tau A, p(A) A\}$ is concave. But let us first observe that, under the assumption that $e_{p}\left(\varepsilon\left(Q_{\max }\right)\right)>-1$ and $\frac{d e_{p}(A)}{d A} \leq 0,(p(A) A)$ is concave since :

$$
\frac{d^{2}}{(d A)^{2}}(p(A) A)=p^{\prime}(A)\left(e_{p}(A)+1\right)+p(A) \frac{d e_{p}(A)}{d A} \leq 0
$$

It follows that $\forall \lambda \in[0,1]$ and $\forall A_{1}, A_{2} \in\left[0, \varepsilon\left(Q_{\max }\right)\right]$

$$
\begin{aligned}
& \min \left\{\tau\left(\lambda A_{1}+(1-\lambda) A_{2}\right), p\left(\left(\lambda A_{1}+(1-\lambda) A_{2}\right)\right)\left(\lambda A_{1}+(1-\lambda) A_{2}\right)\right\} \\
& \left.\geq \min \left\{\lambda \tau A_{1}+(1-\lambda) \tau A_{2}, \lambda p\left(A_{1}\right) A_{1}+(1-\lambda) p\left(A_{2}\right) A_{2}\right\} \text { (concavity of } p(A) A\right) \\
& \left.\geq \lambda \min \left\{\tau A_{1}, p\left(A_{1}\right) A_{1}\right\}+(1-\lambda) \min \left\{\tau A_{2}, p\left(A_{2}\right) A_{2}\right\} \text { (concavity of the } \min \{x, y\}\right)
\end{aligned}
$$

\section{Step 2: Construction of the thresholds}

This program is not smooth but nevertheless concave. This means (see Rockafellar (1997)) that an optimum is reached iff $0 \in \partial_{A} \pi$ where $\partial_{A} \pi$ denotes the sub-derivative of $\pi(A, \tau)$ with respect to $A$. By 
computation, we get:

$$
\partial_{A} \pi= \begin{cases}\underbrace{}_{:=\phi_{m}(\tau)} \underbrace{\tau+p^{\prime}\left(p^{-1}(\tau)\right) p^{-1}(\tau)-\kappa^{\prime}\left(p^{-1}(\tau)\right)}_{p\left(\kappa^{\prime}(A)\right.}, \underbrace{\tau-\kappa^{\prime}\left(p^{-1}(\tau)\right)}_{:=\phi_{c}(\tau)}] & \text { if } A=p^{-1}(\tau) \\ & \text { if } A>p^{-1}(\tau)\end{cases}
$$

Now observe that $\phi_{c}(\tau)=0$ and $\phi_{m}(\tau)=0$ implicitly defines the two thresholds $\tau_{c}$ and $\tau_{m}$. It remains to verify that these thresholds exist, are unique and that $\tau_{c}<\tau_{m}$. These results directly follow from the next observations:

(i) $\phi_{c}$ and $\phi_{m}$ are both increasing. More precisely, $\phi_{c}^{\prime}(\tau)=1-\frac{\kappa^{\prime \prime}\left(p^{-1}(\tau)\right)}{p^{\prime}\left(p^{-1}(\tau)\right)}>0$, and

$$
\begin{aligned}
\phi_{m}^{\prime}(\tau) & =\frac{d}{d \tau}\left(\left(p(A)+p^{\prime}(A) A\right)-\left.\kappa(A)\right|_{A=p^{-1}(\tau)}\right) \\
& =\left.\underbrace{\left(\frac{d^{2}}{(d A)^{2}}(p(A) A)-\kappa^{\prime \prime}(A)\right)}_{<0 \text { (see Eq. (28)) }}\right|_{A=p^{-1}(\tau)} \times \underbrace{\frac{1}{p^{\prime}\left(p^{-1}(\tau)\right)}}_{<0}>0
\end{aligned}
$$

(ii) $\phi_{c}(0)<0$ and $\phi_{m}(0)<0$. Let us remember that $p\left(\varepsilon\left(Q_{\max }\right)\right)=0$ so that $p^{-1}(0)=\varepsilon\left(Q_{\max }\right)$, it follows that $\phi_{c}(0)=-\kappa^{\prime}\left(\varepsilon\left(Q_{\max }\right)\right)<0$ and $\phi_{m}(0)=p^{\prime}\left(\varepsilon\left(Q_{\max }\right)\right) \varepsilon\left(Q_{\max }\right)-\kappa^{\prime}\left(\varepsilon\left(Q_{\max }\right)\right)<0$

(iii) $\phi_{c}\left(\tau_{m}\right)>0$ and $\lim _{\tau \rightarrow+\infty} \phi_{m}(\tau)>0$. The first follows from the fact that $\phi_{c}(\tau)=\phi_{m}(\tau)-$ $p^{\prime}\left(p^{-1}(\tau)\right) p^{-1}(\tau)$ and $\phi_{m}\left(\tau_{m}\right)=0$ so that $\phi_{c}\left(\tau_{m}\right)=-p^{\prime}\left(p^{-1}\left(\tau_{m}\right)\right) p^{-1}\left(\tau_{m}\right)>0$. Concerning the second result, we note:

$$
\lim _{\tau \rightarrow+\infty} \phi_{m}(\tau)=\lim _{\tau \rightarrow+\infty} \tau\left(1+\left.e_{p}(A)\right|_{A=p^{-1}(\tau)}\right)-\lim _{\tau \rightarrow+\infty} \kappa^{\prime}\left(p^{-1}(\tau)\right)
$$

The second term of the r.h.s. is clearly bounded since $p^{-1}(\tau) \in\left[0, \varepsilon\left(Q_{\max }\right)\right]$. If we now remember that $e_{p}(A)$ is decreasing and $e_{p}\left(\varepsilon\left(Q_{\max }\right)\right)>-1$, we have $\lim _{\tau \rightarrow+\infty} \phi_{m}(\tau)=+\infty$.

Step 3: The optimal provision of abatement services

Let us come back to the subdifferential given by Eq. (30). Similar to (i) of Step 2, it can now be argued that the first and the last equation of Eqs. (30) are both decreasing functions. Let us also note that (i) $\lim _{A \rightarrow 0}\left(\tau-\kappa^{\prime}(A)\right)=\tau \geq 0$ and (ii)

$$
\begin{aligned}
& \lim _{A \rightarrow \varepsilon\left(Q_{\max }\right)}\left(p(A)+p^{\prime}(A) A-\kappa^{\prime}(A)\right)=\lim _{A \rightarrow \varepsilon\left(Q_{\max }\right)}\left(p(A)\left(1+e_{p}(A)\right)-\kappa^{\prime}(A)\right) \\
& \left.=-\kappa^{\prime}\left(\varepsilon\left(Q_{\max }\right)\right) \text { (since } p\left(\varepsilon\left(Q_{\max }\right)\right)=0 \text { and } e_{p}(A) \text { bounded }\right)
\end{aligned}
$$

From these observations, and since at a maximum $0 \in \partial_{A} \pi$, we can immediately say that:

(i) if $\phi_{c}(\tau)<0$ or, equivalently, $\tau<\tau_{c}$, the zero of $\partial_{A} \pi$ is given by $\tau-\kappa^{\prime}(A)=0$, so that $A=\left(\kappa^{\prime}\right)^{-1}(\tau)$

(ii) if $\phi_{m}(\tau) \leq 0$ and $\phi_{c}(\tau) \geq 0$, or $\tau \in\left[\tau_{c}, \tau_{m}\right]$, the zero is obtained for $A=p^{-1}(\tau)$

(iii) if $\phi_{m}(\tau)>0$, i.e. $\tau>\tau_{m}$, the optimal provision solves the last equation and this is nothing more than the standard monopoly solution associated with $p(A)$ (i.e. without the kink introduced by the min function).

\section{APPENDIX B: PROOF OF LEMMA 5}

\section{Step 1: Existence of a solution}

Let us denote by $Q=\sum_{j=1}^{m} q_{j}$ and let us take $\min \left\{\tau, p_{A}\right\}$ as given. We observe that (i) the r.h.s. of each equation of Eqs. (20) is increasing in $q_{j}$ since $c_{j}^{\prime \prime}, \varepsilon_{j}^{\prime \prime}>0$ (ii) the range of these functions is $[0,+\infty)$ since $c_{j}^{\prime}(0)=\varepsilon_{j}^{\prime}(0)=0$ and both functions go to $+\infty$ as $q_{j} \rightarrow+\infty$. We can therefore reverse the function given by the r.h.s. and say that $q_{j}=\phi_{j}(Q)$. Moreover, we also observe that (i) $\lim _{Q \rightarrow 0} \phi_{j}(Q)=+\infty$ since $\lim _{Q \rightarrow 0} P(Q)=+\infty$ so that the equality (20) requires that $q_{j} \rightarrow+\infty$, and (ii) $\lim _{Q \rightarrow+\infty} \phi_{j}(Q)=0$ since $\lim _{Q \rightarrow+\infty} P(Q)=0$ and therefore $q_{j} \rightarrow 0$ to maintain the equality.

Let us now aggregate over the $q_{j}$. We obtain $Q=\sum_{j=1}^{m} \phi_{j}(Q)$. So if there exists a solution in $Q$ to this equation our existence problem is solved. It remains to observe that (i) $\Phi(Q)=Q-\sum_{j=1}^{m} \phi_{j}(Q)$ is continuous (ii) $\lim _{Q \rightarrow 0} \Phi(Q)=-\infty$ and (iii) $\lim _{Q \rightarrow+\infty} \Phi_{j}(Q)=+\infty$. 


\section{Damien Sans, Sonia Schwartz and Hubert Stahn}

\section{Step 2: Uniqueness of the solution}

Let us set $K=\min \left\{\tau, p_{A}\right\}$ and write the system (20) as:

$$
\Psi\left(\left(q_{j}\right)_{j=1}^{m}, K\right)=\left(c_{j}^{\prime}\left(q_{j}\right)+K \cdot \varepsilon_{j}^{\prime}\left(q_{j}\right)\right)_{j=1}^{m}-P\left(\sum_{j=1}^{m} q_{j}\right) e \text { with } e^{\prime}=(1, \ldots, 1)
$$

By computation, we observe that $\partial_{\left(q_{j}\right)_{j=1}^{m}} \Psi=D-P^{\prime}\left(\sum_{j=1}^{m} q_{j}\right) e \cdot e^{\prime}$ where $D$ is a diagonal matrix whose generic term is $c_{j}^{\prime \prime}\left(q_{j}\right)+K \varepsilon_{j}^{\prime \prime}\left(q_{j}\right)$. This symmetric matrix is clearly positive definite since $c_{j}^{\prime \prime}, \varepsilon_{j}^{\prime \prime}>$ 0 and $P^{\prime}<0$. It follows from Gale and Nikaido (1965) (Theorem 6) that the solution $\left(q_{j}(K)\right)_{j=1}^{m}$ of $\Psi\left(\left(q_{j}\right)_{j=1}^{m}, K\right)=0$ is unique for every $K$.

Step 3: $A_{f}(K)=\sum_{j=1}^{m} \varepsilon_{j}\left(q_{j}(K)\right)$ is decreasing

Let us first observe from the implicit function theorem applied to $\Psi\left(\left(q_{j}\right)_{j=1}^{m}, K\right)=0$ that $\frac{\partial\left(q_{j}\right)_{j=1}^{m}}{\partial K}=$ $-\left(\partial_{\left(q_{j}\right)_{j=1}^{m}} \Psi\right)^{-1} \cdot\left(\varepsilon_{j}^{\prime}\left(q_{j}\right)\right)_{j=1}^{m}$. It follows that:

$$
\frac{d A_{f}}{d K}=\left(\left(\varepsilon_{j}^{\prime}\left(q_{j}\right)\right)_{j=1}^{m}\right)^{\prime} \cdot \frac{\partial\left(q_{j}\right)_{j=1}^{m}}{\partial K}=-\underbrace{\left(\left(\varepsilon_{j}^{\prime}\left(q_{j}\right)\right)_{j=1}^{m}\right)^{\prime} \cdot\left(\partial_{\left(q_{j}\right)_{j=1}^{m}} \Psi\right)^{-1} \cdot\left(\varepsilon_{j}^{\prime}\left(q_{j}\right)\right)_{j=1}^{m}}_{>0}<0
$$

since the inverse of a positive definite matrix remains positive definite.

\section{APPENDIX C: PROOF OF LEMMA 7}

We need to solve for all $A_{-i} \in\left[0, \varepsilon\left(Q_{\max }\right)\right]$

$$
\max _{a_{i} \in\left[0, \varepsilon\left(Q_{\max }\right)-A_{-i}\right]} \underbrace{\left.\min \left\{\tau, p\left(a_{i}+A_{-i}\right)\right\}\left(a_{i}+A_{-i}\right)-\kappa_{i}\left(a_{i}\right)\right]}_{\pi_{i}\left(a_{i}, A_{-i}, \tau\right)} \text { where } p(A)=\beta\left(\varepsilon^{-1}(A)\right)
$$

Step 1: $\pi_{i}\left(a_{i}, A_{-i}, \tau\right)$ is strictly concave in $a_{-i}$

Under the assumption that $e_{p}\left(\varepsilon\left(Q_{\max }\right)\right)>-1$ and $\frac{d e_{p}(A)}{d A} \leq 0$, we have for $a_{i}>0$ :

$$
\begin{aligned}
0 & >\frac{a_{i}}{A}\left(p^{\prime}(A)\left(e_{p}(A)+1\right)+p(A) \frac{d e_{p}(A)}{d a}\right)=P^{\prime \prime}(A) a_{i}+\frac{2 a_{i}}{A} P^{\prime}(A) \\
& >P^{\prime \prime}(A) a_{i}+2 P^{\prime}(A)=\frac{\partial^{2}}{\left(\partial a_{i}\right)^{2}}\left[p\left(a_{i}+A_{-i}\right) a_{i}\right]
\end{aligned}
$$

We can therefore use the same argument as in Step 1 of Lemma 1 in order to show that $\pi_{i}\left(a_{i}, A_{-i}, \tau\right)$ is strictly concave in $a_{i}$. We simply need to decompose $A$ in $\left(a_{i}+A_{-i}\right)$ and take a convex combination of two $a_{i}$.

\section{Step 2: the subdifferential and the thresholds}

Let us now compute the sub-derivate of $\pi_{i}\left(a_{i}, A_{-i}, \tau\right)$ with respect to $a_{i}$. For $A_{-i}<p^{-1}(\tau)$, we obtain:

$$
\begin{aligned}
& \partial_{a_{i}} \pi= \begin{cases}\tau-\kappa_{i}^{\prime}\left(a_{i}\right) & \text { if } a_{i}<p^{-1}(\tau)-A_{-i} \\
{\left[\varphi_{m}^{i}\left(\tau, A_{-i}\right), \varphi_{c}^{i}\left(\tau, A_{-i}\right)\right]} & \text { if } a_{i}=p^{-1}(\tau)-A_{-i} \\
\underbrace{p\left(a_{i}+A_{-i}\right)+p^{\prime}\left(a_{i}+A_{-i}\right) a_{i}-\kappa_{i}^{\prime}\left(a_{i}\right)}_{:=\psi_{i}\left(a_{i}, A_{-i}\right)} & \text { if } a_{i}>p^{-1}(\tau)-A_{-i}\end{cases} \\
& \text { with } \begin{cases}\varphi_{m}^{i}\left(\tau, A_{-i}\right)=\tau+p^{\prime}\left(p^{-1}(\tau)\right)\left(p^{-1}(\tau)-A_{-i}\right)-\kappa_{i}^{\prime}\left(p^{-1}(\tau)-A_{-i}\right) \\
\varphi_{c}^{i}\left(\tau, A_{-i}\right)=\tau-\kappa_{i}^{\prime}\left(p^{-1}(\tau)-A_{-i}\right)\end{cases}
\end{aligned}
$$

If $A_{-i} \geq p^{-1}(\tau)$, the first and even the second line (if $A_{-i}>p^{-1}(\tau)$ ) are simply vacuous.

So let us for the moment assume that $A_{-i}<p^{-1}(\tau)$ and let us introduce the thresholds $A_{-i}^{c}(\tau)$ and $A_{-i}^{m}(\tau)$ given by $\varphi_{c}^{i}\left(\tau, A_{-i}^{c}(\tau)\right)=0$ and $\varphi_{m}^{i}\left(\tau, A_{-i}^{m}(\tau)\right)=0$. Concerning $A_{-i}^{c}(\tau)$, we observe that (i) $\partial_{A_{-i}} \varphi_{c}^{i}\left(\tau, A_{-i}\right)=\kappa_{i}^{\prime \prime}\left(p^{-1}(\tau)-A_{-i}\right)>0$, (ii) $\varphi_{c}\left(\tau, p^{-1}(\tau)\right)=\tau>0$ and (iii) $\varphi_{c}^{i}(\tau, 0)=\tau-$ $\kappa_{i}^{\prime}\left(p^{-1}(\tau)\right)=\phi_{c}^{i}(\tau)$ this last function being the same as in Eq. (30) but now indexed by agent $i$. So by using Step 2 of the proof of Lemma 1, we know that $\left(\phi_{c}^{i}\right)^{\prime}>0$ and that there exists a unique $\tau_{c}^{i}$ such that 
$\phi_{c}^{i}\left(\tau_{c}^{i}\right)=0$. We can therefore say that:

$$
\left\{\begin{array}{l}
\forall \tau \leq \tau_{c}^{i}, \exists A_{-i}^{c}(\tau) \in\left[0, p^{-1}(\tau)\right], \varphi_{c}\left(\tau, A_{-i}^{c}(\tau)\right)=0 \\
\forall \tau>\tau_{c}^{i}, \varphi_{c}\left(\tau, A_{-i}\right)>0 \text { for all } A_{-i} \in\left[0, p^{-1}(\tau)\right)
\end{array}\right.
$$

Concerning $A_{-i}^{m}(\tau)$, we now observe that (i) $\partial_{A_{-i}} \varphi_{m}^{i}\left(\tau, A_{-i}\right)=\kappa^{\prime \prime}\left(p^{-1}(\tau)-A_{-i}\right)>0$, (ii) $\varphi_{m}^{i}\left(\tau, p^{-1}(\tau)\right)=$ $\tau>0$ and (iii) $\varphi_{m}^{i}(\tau, 0)=\phi_{m}^{i}(\tau)$ this last function again being the same as in Eq. (30)). Again using Step 2 of the proof of Lemma 1, we have:

$$
\left\{\begin{array}{l}
\forall \tau \leq \tau_{m}^{i}, \exists A_{-i}^{m}(\tau) \in\left[0, p^{-1}(\tau)\right], \varphi_{m}^{i}\left(\tau, A_{-i}^{m}(\tau)\right)=0 \\
\forall \tau>\tau_{m}^{i}, \varphi_{m}^{i}\left(\tau, A_{-i}\right)>0 \text { for all } A_{i} \in\left[0, p^{-1}(\tau)\right)
\end{array}\right.
$$

Finally since $\varphi_{m}^{i}\left(\tau, A_{-i}\right)<\varphi_{c}^{i}\left(\tau, A_{-i}\right)$ and both are increasing we can say that for $\tau \leq \tau_{c}^{i}, A_{-i}^{c}(\tau)<$ $A_{-i}^{m}(\tau)$.

Step 3: The unconstrained best response

Let us concentrate on the last equation of Eq. (34). If we compute the associated best response (without regard to $\left.a_{i}>p^{-1}(\tau)-A_{-i}\right)$ we obtain a standard best response $b r_{i}\left(A_{-i}\right)$ which corresponds to a Cournot game in which the inverse demand is $p(A)$. This function exists for all $A_{-i} \in\left[0, \varepsilon^{-1}\left(Q_{\max }\right)\right]$, since (i) $\psi_{i}\left(a_{i}, A_{-i}\right)$ is decreasing in $a_{i}$ (see Step 1 and recall that $\kappa^{\prime}>0$ ), (ii) $\lim _{a_{i} \rightarrow 0} \psi_{i}\left(a_{i}, A_{-i}\right)=$ $p\left(A_{-i}\right)\left(1+e_{p}\left(A_{-i}\right)\right)>0$ since $e_{p}>-1$ by assumption and (iii) $\lim _{a_{i} \rightarrow\left(\varepsilon^{-1}\left(Q_{\max }\right)-A_{-i}\right)} \psi_{i}\left(a_{i}, A_{-i}\right)=$ $-\kappa_{i}^{\prime}\left(\varepsilon^{-1}\left(Q_{\max }\right)-A_{-i}\right)<0$ for $A_{-i}<\varepsilon^{-1}\left(Q_{\max }\right)$ while for $A_{-i}=\varepsilon^{-1}\left(Q_{\max }\right)$ the best response is $a_{i}=0$.

Step 4: The best response

Three cases must be distinguished.

Case 1: $\tau>\tau_{m}^{i}$

In this case we have $\varphi_{c}^{i}\left(\tau, A_{-i}\right)>\varphi_{m}^{i}\left(\tau, A_{-i}\right)>0$. If we now keep in mind that $\left(\tau-\kappa^{\prime}\left(a_{i}\right)\right)$ is decreasing and converges to $\varphi_{c}^{i}\left(\tau, A_{-i}\right)$ as $a_{i} \rightarrow\left(p^{-1}(\tau)-A_{-i}\right), \partial_{a_{i}} \pi$ only admits a zero in the third case of Eq. (34). In other words the best response is $B R_{i}\left(A_{-i}, \tau\right)=b r_{i}\left(A_{-i}\right)$ defined in Step 3.

Case 2: $\tau \in\left(\tau_{c}^{i} ; \tau_{m}^{i}\right]$

Here we know that $\varphi_{c}^{i}\left(\tau, A_{-i}\right)>0$ and therefore $\tau-\kappa_{i}^{\prime}\left(a_{i}\right)>0$ for all $a_{i}<p^{-1}(\tau)-A_{-i}$, but $\exists A_{-i}^{m}(\tau) \in\left[0, p^{-1}(\tau)\right], \varphi_{m}^{i}\left(\tau, A_{-i}^{m}(\tau)\right)=0$. This means that the best response is given by:

$$
B R_{i}\left(A_{-i}, \tau\right)=\left\{\begin{array}{l}
p^{-1}(\tau)-A_{-i} \text { for all } A_{-i} \leq A_{-i}^{m}(\tau) \\
b r_{i}\left(A_{-i}\right) \text { else }
\end{array}\right.
$$

Case 3: $\tau \leq \tau_{c}^{i}$

In this case both thresholds matter so that the best response is given by:

$$
B R_{i}\left(A_{-i}, \tau\right)=\left\{\begin{array}{l}
\left(\kappa_{i}^{\prime}\right)^{-1}(\tau) \text { for all } A_{-i}<A_{-i}^{c}(\tau) \\
p^{-1}(\tau)-A_{-i} \text { for all } A_{-i} \in\left[A_{-i}^{c}(\tau), A_{-i}^{m}(\tau)\right] \\
b r_{i}\left(A_{i}\right) \text { else }
\end{array}\right.
$$

\section{APPENDIX D: PROOF OF LEMMA 4}

\section{Existence:}

Let us first show that for $\tau<\tau_{c}^{\min }$, playing $\left(\kappa_{i}^{\prime}\left(p^{-1}(\tau)\right)\right)_{i=1}^{n}$ is a Nash equilibrium, by showing that it is each player's best response. This follows directly from the definition of $\tau_{c}^{\min }$. In this case we have $\forall i$, $\tau<\kappa_{i}^{\prime}\left(p^{-1}(\tau)\right)$ or $\forall i,\left(\kappa_{i}^{\prime}\right)^{-1}(\tau)<p^{-1}(\tau)$. We can therefore say that:

$$
\forall i \quad A_{-i}^{c}=\sum_{j=1, j \neq i}^{n}\left(\kappa_{j}^{\prime}\right)^{-1}(\tau)<p^{-1}(\tau)-\left(\kappa_{i}^{\prime}\right)^{-1}(\tau)=A_{-i}^{c}(\tau)
$$

This means from Eq. (25) that playing $a_{i}^{C}=\left(\kappa_{i}^{\prime}\right)^{-1}(\tau)$ is a best response for each firm.

Uniqueness:

Concerning uniqueness, let us first observe that the best response (see Eq. (25)) is bounded from above by $\left(\kappa_{i}^{\prime}\right)^{-1}(\tau)$. So if there exists another equilibrium, say $b^{C}$, there must be at least one firm $i_{0}$ such that $b_{i_{0}}^{C}<$ $\left(\kappa_{i_{0}}^{\prime}\right)^{-1}(\tau)$ and, due to the upper bound, $B_{-i_{0}}^{c} \leq \sum_{j=1, j \neq i_{0}}^{n}\left(\kappa_{j}^{\prime}\right)^{-1}(\tau)$. But this leads to a contradiction, 
since for $\tau<\tau_{c}^{\min }$, we have as before that $B_{-i_{0}}^{c}<A_{-i}^{c}(\tau)$, so that $b_{i_{0}}^{C}=\left(\kappa_{i_{0}}^{\prime}\right)^{-1}(\tau)$ should be the best response.

\section{REFERENCES}

AIDT, T. S. (1998): "Political internalization of economic externalities and environmental policy," Journal of Public Economics, 69(1), 1 - 16.

BARRETT, S. (1994): "Strategic environmental policy and international trade," Journal of Public Economics, 54(3), $325-338$.

BRÉCHET, T., AND G. MEUNIER (2014): "Are clean technology and environmental quality conflicting policy goals?," Resource and Energy Economics, 38, 61 - 83.

CAnton, J. (2008): "Redealing the Cards: How an Eco-industry Modifies the Political Economy of Environmental Taxes," Resource and Energy Economics, 30(3), 295 - 315.

CAnton, J., M. David, AND B. Sinclair-Desgagné (2012): "Environmental Regulation and Horizontal Mergers in the Eco-industry," Strategic Behavior and the Environment, 2(2), 107-132.

Canton, J., A. Soubeyran, AND H. Stahn (2008): "Environmental Taxation and Vertical Cournot Oligopolies: How Eco-industries Matter," Environmental and Resource Economics, 40(3), 369-382.

David, M., A.-D. Nimubona, AND B. Sinclair-Desgagné (2011): "Emission taxes and the market for abatement goods and services," Resource and Energy Economics, 33(1), 179 - 191.

DAVID, M., AND B. SinClaIR-DeSGAGNÉ (2005): "Environmental Regulation and the Eco-Industry," Journal of Regulatory Economics, 28(2), 141-155.

Denicolo, V. (1999): "Pollution-reducing innovations under taxes or permits," Oxford Economic Papers, 51(1), 184-199.

Durand, A. L., AND B. Sinclair-Desgagné (2012): "The Growing Business of Mitigating Ecological Footprints," Cirano WP 2012s-07.

ECORYS (2009): "Study on the Competitiveness of EU Eco-industry," techreport Ares 74637 - 15/01/2014, European Commission.

Endres, A., AND T. Friehe (2012): "Market Power in the Eco-industry: Polluters' Incentives under Environmental Liability Law," Land Economics, 88(1), 121-138.

EuRostat (2016a): "Environmental Goods and Services Sector Accounts Handbook 2016 Edition," techreport KS-GQ-16-008, European Commission.

(2016b): "Environmental goods and services sector accounts Practical guide 2016 edition," techreport KS-GQ-16-011, European commision.

FISCHER, C., I. W. H. PARRY, AND W. A. PIZER (2003): "Instrument choice for environmental protection when technological innovation is endogenous," Journal of Environmental Economics and Management, $45(3), 523-545$.

GALE, D., AND H. NiKAIDO (1965): "The Jacobian matrix and global univalence of mappings," Mathematische Annalen, 159(2), 81-93.

Goeschl, T., AND G. Perino (2017): "The Climate Policy Hold-Up: Green Technologies, Intellectual Property Rights, and the Abatement Incentives of International Agreements," The Scandinavian Journal of Economics, 119(3), 709-732.

GREAKER, M. (2006): "Spillovers in the development of new pollution abatement technology: A new look at the Porter-hypothesis," Journal of Environmental Economics and Management, 52(1), 411 - 420.

GREAKER, M., AND K. E. RosendAHL (2008): "Environmental policy with upstream pollution abatement technology firms," Journal of Environmental Economics and Management, 56(3), 246 - 259.

HAHN, R. W. (1984): "Market power and transferable property rights," The Quarterly Journal of Economics, 99(4), 753-765.

HAMILTON, S. F., AND T. REQUATE (2004): "Vertical structure and strategic environmental trade policy," Journal of Environmental Economics and Management, 47(2), 260 - 269.

Katsoulacos, Y., AND A. XepapadeAs (1995): "Environmental policy under oligopoly with endogenous market structure," The Scandinavian Journal of Economics, 97(3), 411-420.

MisIOLEK, W. S., AND H. W. ELDER (1989): "Exclusionary manipulation of markets for pollution rights," Journal of Environmental Economics and Management, 16(2), 156 - 166.

MONTGOMERY, W. (1972): "Markets in licenses and efficient pollution control programs," Journal of Economic Theory, 5(3), $395-418$.

Nimubona, A.-D. (2012): "Pollution Policy and Trade Liberalization of Environmental Goods," Environmental and Resource Economics, 53(3), 323-346. 
Nimubona, A.-D., AND H. Benchekroun (2015): "Environmental R\&D in the Presence of an EcoIndustry," Environmental Modeling and Assessment, 20(5), 491-507.

Nimubona, A.-D., AND B. Sinclair-DesGagné (2011): "Polluters and Abaters," Annals of Economics and Statistics, (103/104), 9-24.

PERINO, G. (2008): "The merits of new pollutants and how to get them when patents are granted," Environmental and Resource Economics, 40(3), 313-327.

(2010): "Technology Diffusion with Market Power in the Upstream Industry," Environmental and Resource Economics, 46(4), 403-428.

PERINO, G., AND T. REQUATE (2012): "Does more stringent environmental regulation induce or reduce technology adoption? When the rate of technology adoption is inverted U-shaped," Journal of Environmental Economics and Management, 64(3), 456 - 467, 2010 Monte Verita Conference on Sustainable Resource Use and Economic Dynamics(SURED).

REQUATE, T. (2005a): "Dynamic incentives by environmental policy instruments: a survey," Ecological Economics, 54(2), 175 - 195, Technological Change and the Environment.

- (2005b): "Timing and Commitment of Environmental Policy, Adoption of New Technology, and Repercussions on R\&D," Environmental and Resource Economics, 31(2), 175-199.

Rockafellar, R. T. (1997): Convex Analysis, Princeton Landmarks in Mathematics. Princeton University Press.

Sans, D., S. Schwartz, AND H. STAhn (2017): "About Polluting Eco-industries: Optimal Provision of Abatement Goods and Pigouvian Fees," Environmental Economics, 8(3), 46-61.

SartZetakis, E. (1997): "Raising Rivals' Costs Strategies via Emission Permits Markets," Review of Industrial Organization, 12(5), 751-765.

SCHWARTZ., S., AND H. STAhN (2014): "Competitive Permit Markets and Vertical Structures: The Relevance of Imperfectly Competitive Eco-Industries," Journal of Public Economic Theory, 16(1), 69-95.

SibaiLly, I. (2013): "On licensing and diffusion of clean technologies in oligopoly," Ecole polytchnique cahier de recherche 2013-24.

SinclaiR-Desgagné, B. (2008): “The Environmental Goods and Services Industry," International Review of Environmental and Resource Economics, 2(1), 69-99.

UNEP (2014): "Measuring the Environmental Goods and Services Sector: Issues and Challenge," techreport, United Nations Environment Programme.

VON DER FEHR, N.-H. (1993): "Tradable emission rights and strategic interaction," Environmental and Resource Economics, 3(2), 129-151.

Westskog, H. (1996): "Market Power in a System of Tradeable $C O_{2}$ Quotas," The Energy Journal, 17(3), $85-103$. 